\title{
The EnvIMS Study: Design and Methodology of an International Case-Control Study of Environmental Risk Factors in Multiple Sclerosis
}

\author{
Sandra Magalhaes ${ }^{a, b} \quad$ Maura Pugliatti $^{c-e} \quad$ Ilaria Casetta $^{f} \quad$ Jelena Drulovic $^{g}$ \\ Enrico Granierif $^{f}$ Trygve Holmøy ${ }^{\text {h, }}$ Margitta T. Kampman $^{j}$

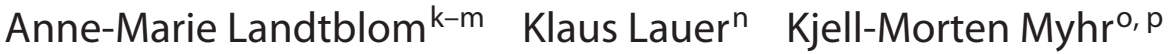 \\ Maria Parpinelq Tatjana Pekmezovic ${ }^{\mathrm{r}}$ Trond Riise ${ }^{\mathrm{d}, \mathrm{o}}$ David Wolfson $^{\mathrm{s}}$ \\ Bin Zhu $^{\text {a }}$ Christina Wolfson ${ }^{\text {a, b, e }}$
}

${ }^{\text {a }}$ Research Institute of the McGill University Health Centre, and ${ }^{b}$ Department of Epidemiology, Biostatistics and

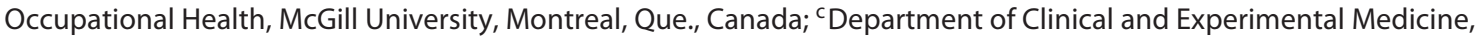
University of Sassari, Sassari, Italy; ${ }^{d}$ Department of Global Public Health and Primary Care, University of Bergen,

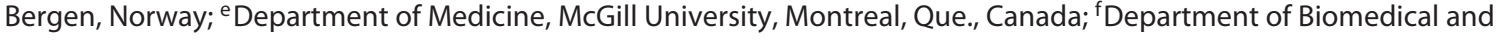
Surgical Sciences, Section of Clinical Neurology, University of Ferrara, Ferrara, Italy; ${ }^{9}$ Clinic of Neurology, Faculty of

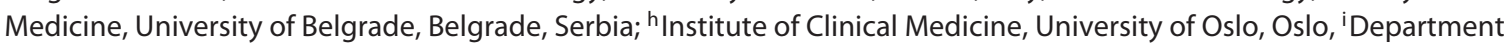
of Neurology, Akershus University Hospital, Lørenskog, and 'Department of Neurology, University Hospital of North Norway, Troms $\varnothing$, Norway; ${ }^{k}$ Department of Neurology and Department of Clinical and Experimental Medicine, Linköping University, Linköping, 'Department of Medical Specialist and Department of Medicine and Health Sciences, Linköping University, Motala, and ${ }^{\mathrm{m}}$ Department of Neuroscience, Uppsala University, Uppsala, Sweden; ${ }^{\mathrm{n}}$ Darmstadt, Germany; ${ }^{\circ}$ The Norwegian Multiple Sclerosis Registry and Biobank, Department of Neurology, Haukeland University Hospital, and PThe KG Jebsen Centre for MS-Research, Department of Clinical Medicine, University of Bergen, Bergen, Norway; ${ }^{9}$ Unit of Hygiene and Epidemiology, Department of Medical and Biological Sciences, University of Udine,

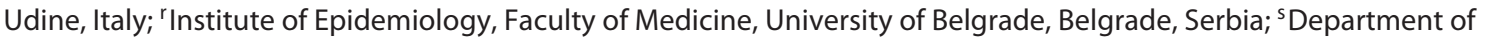
Mathematics and Statistics, McGill University, Montreal, Que., Canada

\section{Key Words}

Multiple sclerosis · Case-control study · Methodology · Etiology · Multinational study · Canada - Italy · Norway . Serbia. Sweden

\section{Abstract \\ Background: Multiple sclerosis (MS) is a chronic disease of the central nervous system, often resulting in significant neurological disability. The causes of MS are not known; however, the incidence of MS is increasing, thereby suggest-}

ing that changes in lifestyle and/or environmental factors may be responsible. On this background, the Environmental Risk Factors in MS Study or EnvIMS study was designed to further explore the etiology of MS. The design and methodology are described, providing details to enable investigators to (i) use our experiences to design their own studies; (ii) take advantage of, and build on the methodological work completed for, the EnvIMS study; (iii) become aware of this data source that is available for use by the research community. Methods: EnvIMS is a multinational case-control study, enrolling 2,800 cases with MS and 5,012 population-based

\section{KARGER 125}

(c) 2015 S. Karger AG, Base

$0251-5350 / 15 / 0443-0173 \$ 39.50 / 0$

E-Mail karger@karger.com

www.karger.com/ned
Dr. Christina Wolfson

Neuroepidemiology Research Unit, Research Institute of the McGill University Health Centre, Royal Victoria Hospital, Allan Memorial Institute

1025 Pine Avenue West, Suite P2.028, Montreal, QC H3A 1A1 (Canada)

E-Mail christina.wolfson@ mcgill.ca 
controls in Canada, Italy, Norway, Serbia and Sweden. The study was designed to investigate the most commonly implicated risk factors for MS etiology using a self-report questionnaire. Results/Conclusions: The use of a common methodology to study MS etiology across several countries enhances the comparability of results in different geographic regions and research settings, reduces the resources required for study design and enhances the opportunity for data harmonization.

(c) 2015 S. Karger AG, Basel

\section{Introduction}

Multiple sclerosis (MS) is a chronic inflammatory disease of the central nervous system, with clinical onset most often between 20 and 40 years of age. The disease is one of the main causes of neurological disability in young adults, leading to substantial costs to society [1] as well as to the individual affected by MS and their families.

The causes of MS are not known, but interactions between genetic and environmental risk factors are hypothesized to trigger the immune-mediated etiopathogenesis of the disease. While genetic changes are likely to have an impact on disease risk slowly, the observed increasing incidence of MS in several regions worldwide $[2,3]$ points to the role of changes in individual lifestyle and/or environmental conditions. Low levels of sun exposure [4-7], low levels of vitamin D [8-11], Epstein-Barr virus (EBV) infection $[12,13]$, cigarette smoking [14-16] have all been shown to be important risk factors for consideration in the study of MS etiology. These risk factors have been suggested to act in childhood and/or adolescence [17-23] and possibly during the perinatal period [24], as determinants of disease risk.

Despite the ultimate goal of identifying modifiable risk factors for MS, research on individuals' history of exposure between birth and disease onset in adulthood is hampered by the long latent period [22] and by the relatively low incidence of MS. While cohort studies are the optimal design to study etiological associations, such studies are challenging to conduct for adult onset MS when early life exposures are of interest. Case-control studies are thus the study design of choice to examine MS etiology. While they do have limitations, an advantage is that they allow for studies to be conducted efficiently and they can be powered to estimate interactions between risk factors, something that has been understudied to date.

On this background, we designed the Environmental Risk Factors in MS Study (EnvIMS study), a large multi- national population-based case-control study. The overall aim was to use a common methodology in the five participating countries (i) to confirm the main effect(s) of commonly implicated environmental risk factors for MS, well supported in the literature and (ii) to assess interactions between risk factors in populations with differing disease risks and possibly different exposure distributions. We report the overall study design and methodology used in the EnvIMS study to provide a common methodology that other investigators may wish to adopt when planning similar studies, which will facilitate comparability of results across studies.

\section{Methods}

Study Design

EnvIMS is a classical case-control study incorporating population-based sampling. After careful consideration of the MS etiologic literature, the primary risk factors of interest and their respective role on the risk of MS were identified: infections (primarily infectious mononucleosis), vitamin D (through sun exposure, dietary intake and supplements), and lifestyle factors (cigarette smoking primarily). The EnvIMS study was designed to explore the differences in prevalence of these risk factors and to assess interactions between selected risk factors in different populations. The study was designed and conducted by investigators located in Canada, Italy, Norway, Serbia and Sweden. Some modifications in design were necessary to accommodate differences across countries. These are described below.

\section{Study Areas}

EnvIMS study coordination and participant recruitment took place in Canada, Italy, Norway, Serbia and Sweden. Study coordination was completed at major academic institutions in each of the five countries. In Canada, the recruitment of participants was conducted to cover three major Canadian cities (Montreal, Toronto and Winnipeg). In Europe, both national and regional level strategies were used to identify and recruit participants. In Norway and Sweden participants were recruited throughout the country, whereas in Italy and Serbia recruitment occurred in specific regions (Sardinia, Ferrara, and Republic of San Marino in Italy, and Belgrade in Serbia). Details about study coordination and sources of participant selection for each of the study locations are provided in table 1.

\section{Cases}

In Europe, cases were identified using national or regional population-based MS registries or databases. In Canada, there are no regional or national MS registries and for this reason, MS cases were identified from the network of MS clinics and a general neurology clinic in the study locations (table 1).

Cases were included if they (i) had a diagnosis of MS according to McDonald [25, 26] or the Poser [27] criteria for clinically and laboratory-supported definite or probable MS; (ii) were 18 years of age or older at the time of the study; and (iii) had disease onset 10 years or less at the time of sampling. Cases selected from MS reg- 
Table 1. Description of the location of EnvIMS study coordination, participant recruitment, and the source of case and control selection

\begin{tabular}{|c|c|c|c|c|}
\hline Country & Study coordination & Participant recruitment & Source of case selection & Source of control selection \\
\hline Canada & McGill University & $\begin{array}{l}\text { Greater Montreal Area, } \\
\text { Greater Toronto Area } \\
\text { and Manitoba } \\
\text { (mainly Winnipeg) }\end{array}$ & $\begin{array}{l}\text { MS clinics } \\
\text { Neurology clinics }\end{array}$ & $\begin{array}{l}\text { Random digit dialing } \\
\text { (http://surveysampler.com) }\end{array}$ \\
\hline Italy & University of Sassari & $\begin{array}{l}\text { Sardinia, Ferrara, and } \\
\text { Republic of San Marino }\end{array}$ & Regional MS registries & $\begin{array}{l}\text { Master file health system of } \\
\text { the region of Sardinia } \\
\text { (ANAGS) [51] }\end{array}$ \\
\hline Norway & University of Bergen & Norway & $\begin{array}{l}\text { Norwegian MS Registry and } \\
\text { Biobank }[34,35]\end{array}$ & $\begin{array}{l}\text { Statistics Norway } \\
\text { (http://www.ssb.no/) }\end{array}$ \\
\hline Serbia & $\begin{array}{l}\text { University of Belgrade } \\
\text { and University of } \\
\text { Sassari }\end{array}$ & Region of Belgrade & Belgrade MS Registry & $\begin{array}{l}\text { Belgrade Institute of Statistics } \\
\text { and Informatics } \\
\text { (https://zis.beograd.gov.rs) }\end{array}$ \\
\hline Sweden & $\begin{array}{l}\text { University of } \\
\text { Linköping }\end{array}$ & $\begin{array}{l}\text { Counties of Östergötland } \\
\text { and Värmland }\end{array}$ & $\begin{array}{l}\text { Östergötland regional database; } \\
\text { Swedish MS Register } \\
\text { (SMSreg http://www.neuroreg.se, } \\
\text { country of Värmland) }\end{array}$ & $\begin{array}{l}\text { Statistics Sweden } \\
\text { (http://www.scb.se) }\end{array}$ \\
\hline
\end{tabular}

istries/databases did not require clinical confirmation of diagnosis; however, in Canada, clinical confirmation of diagnosis was required for study enrolment and this was achieved by working directly with the clinic directors.

\section{Controls}

Sampling of controls was conducted in a way to help ensure that the control-series could be considered the source of the caseseries. The goal was to recruit four times as many controls as cases. The source of controls in each of the five countries is included in table 1 .

In Italy, Norway, Serbia and Sweden population-based sources were also used as the sampling frame for controls. Based on the distribution of cases by sex, year of birth (within 5 years) and health district of residence, a list of potential controls was generated. Four controls for every case were then randomly selected from this list. This final list of controls was crosschecked with the MS registries or databases used, to ensure that no MS case was included in the control series.

In Canada, no population-based register exists from which to sample general population controls, and random digit dialing using local telephone area code was employed to identify controls residing in the same regions from which cases were selected (Greater Montreal Area, Greater Toronto Area, and Manitoba (primarily the city of Winnipeg)). ASDE Survey Sampler, Inc. (http://surveysampler.com), a sampling company, provided a randomly generated list of telephone numbers and addresses. Interviewers phoned each telephone number to determine if there was someone in the household who was eligible to participate and if there was the interviewer obtained verbal consent to mail the participant a questionnaire. MS diagnosis was not ruled out clinically in controls; however, we were able to assess this using self-report, as participants were asked to record in the questionnaire if they had certain medical conditions, including MS.

The EnvIMS Study: Design and Methodology

\section{Questionnaire Development}

Information from participants was obtained using a mailed self-administered questionnaire, the EnvIMS-Q. Details about the EnvIMS-Q development have been described elsewhere (including an online supplement of the actual questionnaires used in each country) [28]. Briefly, EnvIMS-Q was developed first in English to facilitate discussion between all EnvIMS investigators and to enable harmonization across the five countries [29]. The final common questionnaire underwent peer-reviewed translation into Italian, Norwegian, Serbian, Swedish and French [30]. Pilot testing was completed in each of the five countries, and in both English and French in Canada, to assess feasibility, acceptability and reliability. EnvIMS-Q was shown to be cross-culturally acceptable, feasible and reliable [28].

The EnvIMS-Q was identical for cases and controls. Participants were asked to report on demographics and exposure history of the different factors of interest including: mononucleosis infection, sun exposure, cigarette smoke exposure, dietary habits, other lifestyle factors, medical history, and in women hormonal factors were also queried. Specific details about the types of questions used to ascertain the exposure information are provided in Pugliatti et al. [28]. Sun exposure was assessed using various questions that asked participants to report on the frequency of outdoor activities in both summer and winter, during weekends and holidays and for work/occupation. In Canada, Italy and Serbia participants were asked to recall exposure history for five-year fixed intervals of time: $0-5$ years of age, $6-10,11-15,16-20,21-25,26-30$ and in the last 3 years. In Norway and Sweden, age intervals were used that corresponded with their education system (0-6 years, 7-12, 13-15, $16-18,19-24,25-30$ and in the last 3 years). Questions were also asked to ascertain the participants' skin phototype and the use of sunscreen and/or protective clothing during outdoor activities. These questions included ordinal response categories with both descriptive (e.g. not that often - virtually all the time) and numerical 
(e.g. never - more than 4 hours per day) categories. Active smoking was assessed using questions about duration, intensity and frequency of smoking over the age of 11 years (in 5-year age intervals); and passive smoking during childhood and in early adulthood was assessed using questions about the smoking status and intensity of smoking from several potential sources, including mother, father and others smoking inside the house, in addition to occupational exposure. Medical history, which included reporting of infectious mononucleosis, was assessed by asking participants to report diagnosis of a variety of different viruses, infections, allergies, chronic diseases (including MS and other autoimmune diseases), and if so at what age. Participants were also asked to report on family history of several chronic diseases. The questions assessing diet focused on the timing (i.e. season) and frequency of consumption of foods that contain a high vitamin D content (primarily fish and dairy products), during the adolescent period (13-19 years).

As discussed in Pugliatti et al. [28], certain aspects of the EnvIMS-Q were different across countries. For example, (i) a question about sun avoidance and cloth covering is included in the questionnaire used in Italy, (ii) questions about vitamin D dietary intake through dairy products and salad dressings are included in the questionnaires used in Canada, Italy and Serbia, (iii) an entire section about occupational exposures is included in the questionnaires used in Norway and Sweden. In addition, response options for certain questions differed according to the specific setting (e.g. eye color). The quality and look of all the European and the Canadian questionnaires was assured through a common development process, and an agreed-upon layout.

\section{Sample Size Considerations}

The original sample size calculations were based on targeted enrolment of four controls for every case, with the aim to enroll at least 3,000 cases and 12,000 controls. The statistical power for the full study was calculated based on a range of unadjusted odds ratios of 1.2-2.0, using a significance level of 0.05 and conservative estimates of prevalence of risk factors in the general population of 5,10 or $20 \%$. The goal was to ensure a sufficient number of participants were enrolled to allow the precise estimation of modest odds ratios for non prevalent risk factors. The prevalence estimates that were selected are in line with those found in previous MS studies for infectious mononucleosis (5-10\%) [31], low sun exposure ( 10\%) [7], and ever smoking ( 30\%) [16]. It was determined, for example, that nearly $90 \%$ power would be achieved for an odds ratio as small as 1.2 with a risk factor prevalence of $10 \%$. As such, the statistical power is more than adequate to detect significant odds ratios of meaningful size with the targeted sample size.

\section{Recruitment and Data Collection}

Study participant recruitment and data collection were conducted between 2009 and 2010 in Italy, Serbia, between 2009 and 2011 in Norway, between 2012 and 2013 in Canada (the study was conducted later in Canada relative to the other countries because of funding), and between 2009 and 2014 in Sweden (recruitment is ongoing). In Europe, to increase awareness about the study among the general population, advertisements were included in local newspapers, broadcasting and in MS Society mailings. In Canada, cases were approached by the participating neurologists and controls were contacted by telephone for study participation.
In addition, the study was highlighted on the MS Society of Canada webpage.

The EnvIMS-Q was sent to the home of eligible participants, addressed to the specific individual. Each questionnaire included an individual identification number (a barcode in the European countries and a written number in Canada). This number included a code for country area, a code for sex, a code for case or control status, a code for mailing number, and a unique ID code for the specific participant. For example, participant 102010100069 was an individual from Sassari, Italy (1), a female (02) case (01), the first mailing (01) and whose ID number was 00069.

In an effort to increase response rates, several strategies were used $[32,33]$. For all study sites, the mailed envelope included: the EnvIMS-Q; an introductory letter outlining the overall goals of the study; a preaddressed postage-paid return envelope; a study brochure; post-it notes with country-specific sentences to motivate participation; and a colorful logo created specifically for the study was included on all documents. After the initial mailing, if a response was not received within 4-6 weeks, a second mailing with a similar package (reminder letter in place of introductory letter) and the EnvIMS-Q, coded for second mailing, was sent; in Canada, a postcard reminder was sent prior to sending out a second full package.

\section{Data Processing}

Once questionnaires were received, study personnel reviewed them for obvious errors. The questionnaires were then scanned locally into electronic format. The electronic format of the questionnaires was processed by Recogniform Technologies SpA (Rende, Italy) for the questionnaires from the European countries (www.recogniform.com/index.htm), and by the Data Management Unit, McGill University, (Montreal, Que., Canada) for the Canadian questionnaires.

Prior to processing the electronic questionnaires, a set of rules was provided by EnvIMS investigators to identify and address inconsistencies in responses. The process of data extraction was automated, and a conservative threshold was set to identify written or text responses that were inconsistent (below the threshold) and these were checked manually. Several quality assurance steps were included to ensure the quality of the data in the final database, including manual crosscheck of $10 \%$ of randomly selected scanned questionnaires with the paper version and consistency analyses.

\section{Data Consistency and Quality Checks}

A common data dictionary was created for the study databases. Several high-level data consistency and quality checks were performed. The distribution of key variables and the effectiveness of matching were assessed. In addition, we explored the case status in a more detailed manner to determine the concordance between the participants self-report of MS via questionnaire with the registry or clinic reported MS diagnosis. As the exposure information collected in the study includes early life (childhood) exposures, we wondered if participants would seek help in completing the questionnaire. We asked participants to report if they received help from someone to complete the questionnaire and if so, who helped them (e.g. mother, father, both etc.). The degree of missing data for several variables required to assess our primary hypotheses was examined. In addition, a simulation of a complete cases anal- 
Table 2. Response rates and basic characteristics of study participants

\begin{tabular}{|c|c|c|c|c|c|}
\hline & Norway & Sweden ${ }^{b}$ & Italy & Serbia & Canada \\
\hline \multicolumn{6}{|c|}{ Response rate $^{\mathrm{a}}, \mathrm{n}(\%)$} \\
\hline Cases & $953 / 1,368(70)$ & $281 / 381(74)$ & 724/1,692 (43) & $123 / 240(51)$ & 719/868 (83) \\
\hline Controls & $1,717 / 4,728(36)$ & $635 / 1,734(37)$ & $1,338 / 6,414(21)$ & $158 / 1,024(15)$ & $1,146 / 1,938(59)$ \\
\hline \multicolumn{6}{|l|}{ Females, \% } \\
\hline Cases & 70 & 71 & 65 & 60 & 73 \\
\hline Controls & 73 & 79 & 68 & 77 & 66 \\
\hline Cases & $45 \pm 11$ & $44 \pm 11$ & $39 \pm 10$ & $39 \pm 9$ & $42 \pm 11$ \\
\hline Controls & $46 \pm 11$ & $44 \pm 12$ & $39 \pm 11$ & $40 \pm 11$ & $51 \pm 14$ \\
\hline \multicolumn{6}{|c|}{ Disease duration, mean \pm SD } \\
\hline Cases & $7.2 \pm 2.7$ & $6.5 \pm 3.1$ & $5.6 \pm 2.8$ & $6.7 \pm 2.4$ & $6.4 \pm 2.6$ \\
\hline
\end{tabular}

${ }^{\mathrm{a}}$ Response rate = \# questionnaires returned/(\# questionnaires sent - \# questionnaire undeliverable addresses). ${ }^{\mathrm{b}}$ These figures concern only the county of Östergötland, since data collection in Värmland is not yet completed.

ysis using 15 variables was performed to assess the degree of missing data for regression analyses. The most appropriate method used to handle missing data will be determined for each analysis separately.

\section{Ethical Approval}

Ethics approval for the study of human subjects was obtained at each of the participating sites (Canada: McGill University: IRB study n. A01-M16-09B, 28.02.2011; Italy: Sassari ASL1: n. 598/L, 26.04.2007 and 11.05.2009; Olbia-Tempio. ASL 2: n. 33436, 11.06.2009; Comitato Etico. Provincia di Ferrara: n. 11, 18.12.2008; Norway: the Regional Committee for Medical and Health Research Ethics in Western Norway: n. 11259-ANØL, 06.10.2008; Serbia: University of Belgrade, n. 470/XII-13, 29.12.2008; Sweden: Ethical Committee (EPN) in South East Region n. M159-09). Return of the questionnaire was considered to be implied consent.

\section{Funding}

An innovative funding strategy was required to enable the full study to be conducted in each participating country. This work was supported by the University of Bergen, Norway (2007 to T. Riise) and the Canadian MS Scientific Research Foundation (2009-2010 to C. Wolfson) for the early planning stages of the study, including the pilot studies [28]. To conduct the full study in Europe, the work was supported by the: Italian MS Society/Foundation (Fondazione Italiana Sclerosi Multipla, FISM, grants n. 2007/R/14, and n. 2008/R/19 to M. Pugliatti); Sardinian Autonomous Regional Administration, Italy (Regione Autonoma della Sardegna, Assessorato all'Igiene, Sanità e dell'Assistenza Sociale to M. Pugliatti); the Fondazione Banco di Sardegna, Italy; The Western Norway Regional Health Authority (Helse Vest) Norway (grants n. 911421/2008 to M. Pugliatti and n. 911474/2009 to K.-M. Myhr); and Norwegian MS Society (MS-forbundet i Norge, 2009 to T. Riise); Funds for Clinical Research University Hospital Linköping, Sweden (2010-2011 to A.M. Landtblom). To conduct the full study in Canada, the work was supported by the Multiple Sclerosis Society of Canada (2011-2013 to C. Wolfson).

The EnvIMS Study: Design and Methodology

\section{Results}

A brief overview of the overall study response rates, the balance of the frequency matching (age and sex), as well as disease duration in cases, is provided in table 2.

The overall response rate was higher for cases than that for controls and this finding was consistent in all countries. The response rate in Canada appears to be higher than the other countries. However, the sampling strategy used in Canada required an additional layer of consent, as both cases and controls had to verbally agree to receive the EnvIMS-Q. Clinic staff approached eligible MS cases and telephone interviewers contacted potential controls by telephone to determine study eligibility. When incorporating this additional layer of the consent process for control recruitment in Canada, the response rate is in line with what is reported for control recruitment in the other EnvIMS countries ( $30 \%$; data not shown). In addition, to assess a methodology for participant recruitment that mirrors that used in the European countries, questionnaires were mailed without initial contact via telephone in 390 of telephone numbers/addresses received, and 104 questionnaires were returned $(27 \%)$, which was also in line with the response rates reported in the European countries. Among responders, the majority responded to the first mail sent (range 70-90\%), while the remainder responded only after the second mail was sent. During the same time that case recruitment was underway in Norway, the Norwegian MS Registry and Biobank $[34,35]$ was updated and was queried a second time to determine if any additional cases were eligible for participation. This second round of case recruitment took place in 2011 and had 
a response rate of $77 \%(150 / 195)$ of whom $80 \%$ responded to the first mailing.

Data consistency analyses were completed in the first round of review of the data collected. Inconsistencies were identified when assessing the study inclusion criteria. In Norway and Italy a small number of participants were under the age of 18 at the time of study. These individuals could not be included in any analyses as they did not meet the inclusion criteria. A small proportion of cases in Norway (13\%) and in Sweden (17\%) had disease duration greater than 10 years, but all had disease duration less than 12 years, as such these individuals will remain in the dataset. Both cases and controls were asked to report if a doctor had ever told them that they had MS. Among those responding to the question 'Has a doctor ever told you that you had MS?' 94 to $99 \%$ of cases responded 'yes', whereas only 0.002 to $0.1 \%$ of controls responded 'yes'. In Canada, MS was not ruled out clinically in controls; however, based on self-report a negligible proportion $(0.1 \%)$ of controls in Canada reported having MS. A fair number of participants reported receiving help completing the questionnaire. A greater proportion of cases (44-50\%) than controls $(20-30 \%)$ received help completing the questionnaire and most participants received help from their mother (64-76\%).

Missing data have been assessed for the variables required to address the main hypotheses. Overall, the proportion of missing data on sun exposure and smoking questions was low $(<10 \%)$, whereas the proportion of missing data for the mononucleosis infection questions was as high as $17 \%$ in cases in Italy. The overall proportion of missing data was also assessed by simulating a complete case analysis using a set of 15 variables that assessed MS diagnosis information, exposure to cigarette smoking (both passive and active) and of exposure to infection with mononucleosis. Using these 15 variables, the range of participants with complete data ranged from only $50 \%$ in both cases and controls in Italy, to as high as $84 \%$ in controls in Norway.

Cases and controls were frequency matched on age and sex. Among the respondents, the distribution of sex was similar in all countries (60-70\% of females among cases versus 66-79\% among controls) except for Serbia. The distribution of ages at the time of study was also similar in each of the countries. To ensure that the exposure opportunities for cases and controls were frequency matched, we used an index age assignment method [36]. We used an algorithm that assigns each control an index age corresponding to the age at onset of a case with a similar current age [36]. In an attempt to reduce issues related to sampling prevalent cases, the goal was to recruit cases as close as possible to disease onset. The average disease duration in cases ranged between 5 and 7 years in the 5 countries.

\section{Discussion}

The methodology used to design and conduct a large multi-country case-control study for etiological research in MS, the EnvIMS study, is described. The aim of the study was to assess the effect of past exposure to environmental and lifestyle factors on the risk of developing MS. Detailing the design and methodology used in the EnvIMS study offers other investigators a guide to a common methodology for the design of a case-control study in different geographic regions and research settings.

Carrying out a multinational case-control study, such as the EnvIMS study, is a complex challenge. The process involved a high level of commitment from study investigators with different expertise to: establish an efficient network; design the study; develop the questionnaire; obtain funding and ethical approval; coordinate with national and regional registries or databases in Europe and identify compatible alternatives in Canada to ascertain eligible cases and controls; and to create a cohesive data collection and processing platform in attempts to obtain high response rates and ensure data quality.

Given the multi-country nature of the EnvIMS study, country-specific modifications in study methodology were required. However, ensuring a similar base methodology will facilitate harmonization across the five countries and increase comparability of final results [29]. In addition, the use of a common questionnaire, the EnvIMS-Q, the quality of harmonization is substantially increased. Our group has carried out some cross-cultural validation work on the EnvIMS-Q and the questionnaire is available to the research community [28]. To date, EnvIMS investigators have been approached by several researchers interested in using the EnvIMS-Q in new studies designed to assess the etiology of MS. Researchers interested in using the EnvIMS-Q to collect exposure history data in their studies are encouraged to contact the EnvIMS Steering Committee members (Drs. Myhr, Pugliatti, Riise and Wolfson) for more information about adapting and using the questionnaire in different research settings. Collecting exposure information consistently and transparently across many studies will allow for more complex meta-analyses, as more detailed vari- 
able definitions can be used. A unified or harmonized approach to the international study on the etiology of MS may help to elucidate geographical similarities (universal etiological factors) and differences (population-specific risk factors).

In line with the goals of the EnvIMS study, a casecontrol study design was used to elicit information about exposure to several MS risk factors. Cohort studies, in which information on exposure(s) is collected during a time prior to the onset of the disease, are the ideal observational study design to assess etiology. Though powerful, prospective cohort studies specifically designed to study MS etiology are generally not feasible, due to the fact that MS is relatively rare and has a long latent period that would require the long-term follow-up of a large number of study participants, which is both financially and logistically restrictive. Large cohorts that have been established for other research purposes, such as the Nurses' Health Study, have been used to explore MS etiology [10, 11, 31, 37-47]. However, the type of risk factors that can be assessed is limited by what has already been collected.

Case-control studies are often criticized due to the increased potential for bias. The EnvIMS study was designed in an attempt to reduce the impact of these biases on the study results. This included using the same study materials for both cases and controls, enrolling cases with short disease duration (or incident cases), sampling of the controls so they were representative of the population from which cases arose, enrolling more than one control per case and frequency-matching cases and controls on major confounders.

Data collected through the EnvIMS study are accessible to the research community upon request, following approval of the EnvIMS Steering Committee (Drs. Myhr, Pugliatti, Riise and Wolfson). Data access procedures and application forms have been created for this purpose. To gain access to the data, researchers must provide details about their proposed project including: a title, short background, rationale, specific aims, and the proposed analysis plans. Those requesting data should specify the country-specific dataset(s) and the specific variables required. Researchers are encouraged to review the EnvIMS-Q [28] to identify and select specific variables for analysis. While the use of EnvIMS data by the research community is encouraged, the process of data access is necessary to monitor the quality of the work being completed using these data and to avoid unnecessary duplication of work on the same hypothesis by different groups. To date, data collected through the EnvIMS study has been used to assess the relationship between the season of infection mononucleosis [48], sun exposure [49], and body size [50], and the risk of MS.

In conclusion, the EnvIMS study is among the largest case-control studies conducted on MS etiology. The inclusion of five countries allows for assessment of similarities and differences across countries, which is enhanced by the use of the same base methodology and questionnaire. The large sample size and consequently high statistical power, allows for precise estimation of risk and assessment of interactions between risk factors. The methodological development completed as part of this study, in particular the EnvIMS-Q, is available to the research community. Accessibility to this rich data source is also possible using the established procedures described earlier. Collaboration was a major factor in the success of the EnvIMS study, and the goal is to continue to expand collaborations to facilitate further MS etiologic studies and comparability of results obtained.

\section{Acknowledgements}

The authors acknowledge the participants of the study in Canada, Italy, Norway, Serbia and Sweden. As well we would like to acknowledge: Dr. Alberto Ascherio (Department of Nutrition, Department of Epidemiology, Harvard Medical School, Boston, USA) for advice in the early planning stages; Ms. Zorana Djordjevic, Natasa Ognjanovic and Biljana Buljugic for Serbian translation, and Professor Gordana Ristic as nutritionist for Serbian EnvIMSQ; Dr. Bettina Galanti, Dr. Angela Gandin, Dr. Giannina Arru (Department of Clinical and Experimental Medicine, University of Sassari, Italy), Ms. Mari Riise (Department of Public Health and Primary Health Care, University of Bergen, Norway); Dr. Bryna Shatenstein as nutritionist for the Canadian EnvIMS-Q (University of Montreal, Canada); Ms. Sally Killborn and Elaina T. Uniat for administrative and research assistance for the Canadian pilot study and Dr. Catherine Tansey as coordinator for the Canadian study (Neuroepidemiology Research Institute, RI MUHC, Montreal, Canada); RN Sabine Richter (Department of Neurology, Linköping University Hospital, Sweden).

For identification of cases and controls and quality of control on dataset: Italy, Sardinia: Dr. Paola Cossu, Dr. Stefania Leoni, Dr. Leslie D. Parish, Dr. M. Immacolata Pirastru (U.O. di Clinica Neurologica, Azienda Ospedaliero-Universitaria, Sassari); Dr. Sebastiano Traccis, Dr. Enzo Ortu (Divisione di Neurologia, Ospedale S. Francesco, ASL 1, Ozieri); Dr. Piergiorgio Annicchiarico, Dr. Iolanda Spano (Direzione Generale, Settore Servizi Informativi, ASL 1, Sassari); Dr. Giuseppe Mura (Servizio di Neurologia, Ospedale S. Giovanni di Dio, ASL 2, Olbia); Dr. Anna Ticca (Divisione di Neurologia, Ospedale di Nuoro, ASL 3, Nuoro); Dr. M. Giovanna Marrosu, Dr. Eleonora Cocco (Centro Sclerosi Multipla, Ospedale Binaghi, ASL 8, Cagliari). Italy, Ferrara: Dr. Riccardo DeGennaro (Dipartimento di Scienze Biomediche e Chirurgiche, Sezione di Neurologia, Università di Ferrara). Republic of San 
Marino: Dr. Chiara Monaldini. Norway, Bergen: Dr. Kristin Wesnes, Dr. Kjetil Lauveland Bjørnevik. Sweden: Dr. Rune Johansson, (Central Hospital Karlstad of Karlstad, Sweden); Inger Boström, PhD (Linköping University). Serbia: Dr. Sarlota Mesaros, Dr. Irena Dujmovic (Clinic of Neurology, Faculty of Medicine, University of Belgrade, Belgrade, Serbia); Dr. Darija Kisic Tepavcevic (Institute of Epidemiology, Faculty of Medicine, University of Belgrade, Belgrade, Serbia). Canada, Montreal: Dr. Pierre Duquette, Dr. Yves Lapierre, Erin Lundy, Azedeh Shohoudi, and the telephone interviewers who conducted random digit dialing to identify controls. Canada, Toronto: Dr. Liesley Lee. Canada, Winnipeg: Dr. Ruth Ann Marrie.

\section{Disclosure Statement}

The authors declare that they have no conflict of interest.

\section{References}

1 Gustavsson A, Svensson M, Jacobi F, Allgulander C, Alonso J, Beghi E, et al: Cost of disorders of the brain in Europe 2010. Eur Neuropsychopharmacol 2011;21:718-779.

2 Koch-Henriksen N, Sørensen PS: Why does the north-south gradient of incidence of multiple sclerosis seem to have disappeared on the northern hemisphere? J Neurol Sci 2011;311: 58-63.

3 Koch-Henriksen N, Sørensen PS: The changing demographic pattern of multiple sclerosis epidemiology. Lancet Neurol 2010;9:520532.

4 Dalmay F, Bhalla D, Nicoletti A, Cabrera-Gomez JA, Cabre P, Ruiz F, et al: Multiple sclerosis and solar exposure before the age of 15 years: case-control study in Cuba, Martinique and Sicily. Mult Scler 2010;16:899-908.

5 Harbo HF, Utsi E, Lorentzen AR, Kampman MT, Celius EG, Myhr KM, et al: Low frequency of the disease-associated DRB1*15DQB1*06 haplotype may contribute to the low prevalence of multiple sclerosis in Sami. Tissue Antigens 2007;69:299-304.

6 Islam T, Gauderman WJ, Cozen W, Mack TM: Childhood sun exposure influences risk of multiple sclerosis in monozygotic twins. Neurology 2007;69:381-388.

7 van der Mei IA, Ponsonby AL, Dwyer T, Blizzard L, Simmons R, Taylor BV, et al: Past exposure to sun, skin phenotype, and risk of multiple sclerosis: case-control study. BMJ 2003;327:316.

8 Munger KL, Levin LI, Hollis BW, Howard NS, Ascherio A: Serum 25-hydroxyvitamin D levels and risk of multiple sclerosis. JAMA 2006; 296:2832-2838.

9 Ascherio A, Munger KL, Simon KC: Vitamin D and multiple sclerosis. Lancet Neurol 2010; 9:599-612.

10 Munger KL, Zhang SM, O’Reilly E, Hernán MA, Olek MJ, Willett WC, et al: Vitamin D intake and incidence of multiple sclerosis. Neurology 2004;62:60-65.

11 Munger KL, Chitnis T, Frazier AL, Giovannucci E, Spiegelman D, Ascherio A: Dietary intake of vitamin D during adolescence and risk of multiple sclerosis. J Neurol 2011;258: 479-485.

12 Banwell B, Krupp L, Kennedy J, Tellier R, Tenembaum S, Ness J, et al: Clinical features and viral serologies in children with multiple sclerosis: a multinational observational study. Lancet Neurol 2007;6:773-781.

13 Levin LI, Munger KL, O'Reilly EJ, Falk KI, Ascherio A: Primary infection with the Epstein-Barr virus and risk of multiple sclerosis. Ann Neurol 2010;67:824-830.

14 Maghzi AH, Etemadifar M, Heshmat-Ghahdarijani K, Moradi V, Nonahal S, Ghorbani A, et al: Cigarette smoking and the risk of multiple sclerosis: a sibling case-control study in Isfahan, Iran. Neuroepidemiology 2011;37: 238-242.

15 Hawkes $\mathrm{CH}$ : Smoking is a risk factor for multiple sclerosis: a metanalysis. Mult Scler 2007; 13:610-615.

16 Riise T, Nortvedt MW, Ascherio A: Smoking is a risk factor for multiple sclerosis. Neurology 2003;61:1122-1124.

17 Alter M, Kahana E, Loewenson R: Migration and risk of multiple sclerosis. Neurology 1978;28:1089-1093.

18 Dean G, McLoughlin H, Brady R, Adelstein AM, Tallett-Williams J: Multiple sclerosis among immigrants in Greater London. $\mathrm{Br}$ Med J 1976;1:861-864.

19 Elian M, Nightingale S, Dean G: Multiple sclerosis among United Kingdom-born children of immigrants from the Indian subcontinent, Africa and the West Indies. J Neurol Neurosurg Psychiatry 1990;53:906-911.

20 Gale CR, Martyn CN: Migrant studies in multiple sclerosis. Prog Neurobiol 1995;47:425448.

21 Pugliatti M, Riise T, Sotgiu MA, Satta WM, Sotgiu S, Pirastru MI, et al: Evidence of early childhood as the susceptibility period in multiple sclerosis: space-time cluster analysis in a Sardinian population. Am J Epidemiol 2006; 164:326-333.

22 Wolfson C, Wolfson DB: The latent period of multiple sclerosis: a critical review. Epidemiology 1993;4:464-470.

23 Wolfson C, Wolfson DB, Zielinski JM: On the estimation of the distribution of the latent period of multiple sclerosis. Neuroepidemiology 1989;8:239-248.

24 Gardener H, Munger KL, Chitnis T, Michels $\mathrm{KB}$, Spiegelman D, Ascherio A: Prenatal and perinatal factors and risk of multiple sclerosis. Epidemiology 2009;20:611-618.
25 McDonald WI, Compston A, Edan G, Goodkin D, Hartung HP, Lublin FD, et al: Recommended diagnostic criteria for multiple sclerosis: guidelines from the international panel on the diagnosis of multiple sclerosis. Ann Neurol 2001;50:121-127.

26 Polman CH, Reingold SC, Edan G, Filippi M, Hartung HP, Kappos L, et al: Diagnostic criteria for multiple sclerosis: 2005 revisions to the 'McDonald criteria'. Ann Neurol 2005;58: 840-846.

27 Poser CM, Paty DW, Scheinberg L, McDonald WI, Davis FA, Ebers GC, et al: New diagnostic criteria for multiple sclerosis: guidelines for research protocols. Ann Neurol 1983;13:227-231.

28 Pugliatti M, Casetta I, Drulovic J, Granieri E, Holmøy T, Kampman MT, et al: A questionnaire for multinational case-control studies of environmental risk factors in multiple sclerosis (EnvIMS-Q). Acta Neurol Scand Suppl 2012;195:43-50.

29 Magalhaes S, Wolfson C: Harmonization: a methodology for advancing research in multiple sclerosis. Acta Neurol Scand Suppl 2012; 195:31-35.

30 Sperber AD: Translation and validation of study instruments for cross-cultural research. Gastroenterology 2004;126(1 suppl 1):S124S128.

31 Hernán MA, Zhang SM, Lipworth L, Olek MJ, Ascherio A: Multiple sclerosis and age at infection with common viruses. Epidemiology 2001;12:301-306.

32 Edwards P, Roberts I, Clarke M, DiGuiseppi C, Pratap S, Wentz R, et al: Increasing response rates to postal questionnaires: systematic review. BMJ 2002;324:1183.

33 Dillman D, Smyth J: Mail and Internet Surveys: The Tailored Design Method, ed 2. John Wiley \& Sons, Inc., 2000.

34 Myhr KM, Grytten N, Aarseth JH, Nyland H: The Norwegian multiple sclerosis national competence centre and national multiple sclerosis registry - a resource for clinical practice and research. Acta Neurol Scand Suppl 2006;183:37-40.

35 Myhr KM, Grytten N, Aarseth JH: The Norwegian multiple sclerosis registry and biobank. Acta Neurol Scand Suppl 2012;195: 20-23. 
36 Lundy E: The Effect of Assigning Different Index Dates for Control Exposure Measurement on Odds Ratio Estimates. Master's thesis, McGill University, 2012. http://digitool.library. mcgill.ca/webclient/StreamGate?folder id $=0 \&$ dvs $=1429825295784 \sim 471$.

37 Hernán MA, Hohol MJ, Olek MJ, Spiegelman D, Ascherio A: Oral contraceptives and the incidence of multiple sclerosis. Neurology 2000;55:848-854.

38 Ascherio A, Munger KL, Lennette ET, Spiegelman D, Hernán MA, Olek MJ, et al: Epstein-Barr virus antibodies and risk of multiple sclerosis: a prospective study. JAMA 2001; 286:3083-3088.

39 Hernán MA, Olek MJ, Ascherio A: Cigarette smoking and incidence of multiple sclerosis. Am J Epidemiol 2001;154:69-74.

40 Zhang SM, Hernán MA, Olek MJ, Spiegelman D, Willett WC, Ascherio A: Intakes of carotenoids, vitamin $\mathrm{C}$, and vitamin $\mathrm{E}$ and MS risk among two large cohorts of women. Neurology 2001;57:75-80.
41 Wagner HJ, Munger KL, Ascherio A: Plasma viral load of Epstein-Barr virus and risk of multiple sclerosis. Eur J Neurol 2004;11:833-834.

42 Alonso A, Hernán MA, Ascherio A: Allergy, family history of autoimmune diseases, and the risk of multiple sclerosis. Acta Neurol Scand 2008;117:15-20.

43 Munger KL, Chitnis T, Ascherio A: Body size and risk of MS in two cohorts of US women. Neurology 2009;73:1543-1550.

44 Simon KC, van der Mei IA, Munger KL, Ponsonby A, Dickinson J, Dwyer T, et al: Combined effects of smoking, anti-EBNA antibodies, and HLA-DRB1*1501 on multiple sclerosis risk. Neurology 2010;74:1365-1371.

45 Mirzaei F, Michels KB, Munger K, O’Reilly E, Chitnis T, Forman MR, et al: Gestational vitamin $\mathrm{D}$ and the risk of multiple sclerosis in offspring. Ann Neurol 2011;70:30-40.

46 Kister I, Munger KL, Herbert J, Ascherio A: Increased risk of multiple sclerosis among women with migraine in the Nurses' Health Study II. Mult Scler 2012;18:90-97.
47 Massa J, O'Reilly EJ, Munger KL, Ascherio A Caffeine and alcohol intakes have no association with risk of multiple sclerosis. Mult Scler 2013;19:53-58.

48 Lossius A, Riise T, Pugliatti M, Bjørnevik K, Casetta I, Drulovic J, et al: Season of infectious mononucleosis and risk of multiple sclerosis at different latitudes; the EnvIMS study. Mult Scler 2014;20:669-674

49 Bjørnevik K, Riise T, Casetta I, Drulovic J, Granieri E, Holmøy T, et al: Sun exposure and multiple sclerosis risk in Norway and Italy: the EnvIMS study. Mult Scler 2014;20:10421049.

50 Wesnes K, Riise T, Casetta I, Drulovic J, Granieri E, Holmøy T, et al: Body size and the risk of multiple sclerosis in Norway and Italy: the EnvIMS study. Mult Scler 2015;21:388-395.

51 Santer Reply: ANAGS: The Master File Health System of the Region of Sardinia www.reply. eu/Documents/2052_img_SANR09. ANAGS_sardegna_eng.pdf (cited August 28, 2014). 